\title{
Por que a sociedade brasileira precisa de um licenciado em dança para seu ensino em uma perspectiva artística e inclusiva?
}

Why does Brazilian society need a dance licensee for its teaching in an artistic and inclusive perspective?

\author{
Elisabeth Bauch Zimmermann ${ }^{1}$ \\ Ana Carla de Assis Ribeiro ${ }^{2}$ \\ Tânia de Carvalho Fonseca ${ }^{3}$
}

\section{Resumo}

Encontra-se aqui um estudo sobre o ensino inclusivo da dança, com foco em dois grupos específicos: idosos e deficientes visuais - com os quais as pesquisadoras trabalharam em suas práticas pedagógicas. Este trabalho parte da educação inclusiva, estudando o ensino para aqueles que nem sempre tiveram acesso à dança, por conta de deficiências ou restrições físicas decorrentes de processos naturais ou adquiridos. Com isso busca-se ampliar as possibilidades de atuação no ensino da dança e, principalmente, evidenciar os benefícios da formação da licenciatura em dança para que os professores atuem em uma perspectiva inclusiva. $O$ trabalho contém também, reflexões a respeito das transformações pessoais e coletivas nos indivíduos envolvidos nesses processos.

Palavras-chave: Dança inclusiva. Deficientes visuais. Idosos. Ensino de Dança.

\footnotetext{
1 Universidade Estadual de Campinas. Professora do Programa de Pós-Graduação em Artes da Cena e dos Cursos de Bacharelado e Licenciatura em Dança. ORCID: https://orcid.org/0000-0003-11640719 Contato: zimmandrade@gmail.com

2 Bacharel e Licenciada em Dança pela Universidade Estadual de Campinas. ORCID: https:/ / orcid.org/0000-0002-5228-2922 Contato: aassisribeiro@gmail.com

3 Bacharel e Licenciada em Dança pela Universidade Estadual de Campinas. ORCID: https:// orcid.org/0000-0002-1568-7269 Contato: tacfonseca@yahoo.com.br
} 
Conceição | Conception

Revista do Programa de Pós-Graduação em Artes da

Cena, Universidade Estadual de Campinas

Performing Arts Graduate Program Journal, University of

Campinas

\begin{abstract}
Here is a study on inclusive dance education focusing on two specific groups: the elderly and the visually impaired - with whom the researchers worked on their studies. This work is part of inclusive education, studying education for those who did not always have space in dance, due to deficiencies or physical restrictions arising from natural or acquired processes. With this, the aim is to broaden the possibilities of the professionals of dance teaching and to highlight the benefits of the training of the graduation in dance for those who work with such people, containing in this work ideas on how to work with this distinguished public. It also contains reflections on personal and collective transformations of the individuals involved in these processes.
\end{abstract}

Keywords: Inclusive dance. Visually impaired. Seniors. Dance Teaching.

A formação em dança pode acontecer dentro e fora da universidade. Em sua maior parte acontece fora dela, uma vez que existem cerca de cinquenta cursos de graduação em dança, enquanto que há centenas de academias e estúdios livres distribuídos pelo Brasil inteiro. Entretanto, a graduação em dança permite que o bailarino ou licenciado tenha uma visão diferenciada sobre essa área educacional e artística, tendo acesso a conteúdos teóricos e reflexivos sobre a dança, que nem sempre estão presentes nas academias. Estas visam, em sua maioria, o aprendizado de determinados estilos de dança, a repetição de sequências de movimentos e o produto final, com a expectativa de atingir uma perfeição da forma e do conteúdo da obra a ser apresentada.

O licenciado em dança, por sua vez, consegue refletir sobre as diversas maneiras de atuar em sua área, a partir das teorias da educação, da arte em geral e da dança especificamente. "Na dança educação, o educador assume o papel de facilitador das descobertas, valorizando e estimulando a potencialidade de cada bailarino, além de obter uma postura auto-reflexiva da sua prática" (LIMA, 2002, p. 12). 
Conceição | Conception

Revista do Programa de Pós-Graduação em Artes da

Cena, Universidade Estadual de Campinas

Performing Arts Graduate Program Journal, University of

Campinas

O que caracteriza (também) o ensino na universidade é a experimentação, a pesquisa teórica e o estudo de técnicas e métodos de improvisação e composição, que são ferramentas para o desenvolvimento de processos de criação. Na academia, o amadurecimento técnico é um dos principais objetivos, enquanto na universidade a ênfase é colocada no estudo das diversas abordagens, clássicas, modernas, populares, contemporâneas, entre outras, que constituem a dança nacional e internacional. Além disso, há disciplinas específicas para a atuação dentro da educação especial na perspectiva da educação inclusiva, assim como sobre formas de ensinar dança para grupos com demandas educacionais especiais, incluindo os deficientes visuais e os idosos, que são os focos de estudo deste texto.

Durante a formação na universidade tem-se a possibilidade de estudar a dança de forma abrangente, incluindo disciplinas em que se desenvolvem várias teorias e práticas que facilitam uma abordagem inclusiva do ensino. Procura-se desenvolver competências no futuro professor de dança, por meio de disciplinas ministradas de forma reflexiva e não exclusivamente tecnicista, além das próprias disciplinas teóricas. Apresentamos como exemplo o curso em que realizamos nossa formação.

O projeto pedagógico ${ }^{4}$ do curso de Licenciatura em Dança da Unicamp propõe um percurso de formação composto por seis núcleos de aprendizagem: Formação Específica Técnico-Artística; Fundamentação de Área; Fundamentação Pedagógica; Práticas de Ensino; Estágio Curricular Supervisionado; Atividades Científico Culturais; e, Eletivas. Dentro desses núcleos há especificidades que podem trazer diversos conhecimentos e reflexões que servem para habilitar e incentivar um profissional a lidar com diferentes públicos. Logo abaixo estão indicadas algumas das disciplinas que compõem esses núcleos e seus propósitos:

1 - Fundamentação de Área: aqui estão tanto disciplinas que focalizam os estudos de anatomofiológicos e biomecânicos do corpo e do movimento, como os

\footnotetext{
$4 \mathrm{O}$ presente texto apoiou-se em dados do projeto em vigor em 2016. No ano de 2018, o projeto pedagógico do curso de Licenciatura em Dança da Unicamp passou por uma reformulação.
} 
Conceição | Conception

Revista do Programa de Pós-Graduação em Artes da

Cena, Universidade Estadual de Campinas

Performing Arts Graduate Program Journal, University of

Campinas

estudos históricos, culturais e estéticos da dança. Neste caso, nas disciplinas História da Dança I e II e História da Dança no Brasil propõe-se, por exemplo, o estudo teórico, além da reflexão crítica sobre espetáculos assistidos, assim como incentiva-se os alunos a frequentarem diversos espaços artísticos e a assistirem a apresentações de variadas linguagens cênicas.

2 - Formação Específica Técnico-Artística: as disciplinas deste núcleo permitem a prática em dança de maneira experimental e reflexiva. Inclui Ateliê de Prática e Ensino da Dança I e II, Ateliês de Criação I ao VI, Técnica em Dança: I e II Investigação e Percepção, III e IV - Prática, Análise e Ensino da Dança, V e VI Variação e Exploração, VII e VIII - Expressão e Integração, e Danças do Brasil I a IV.

3 - Fundamentação Pedagógica: algumas das disciplinas - Escola e Cultura, Psicologia e Educação, Política Pública: Estrutura e Funcionamento da Ed. Bras. e Libras e Educação de Surdos - deste núcleo ocorrem na Faculdade de Educação, permitindo o contato com alunos de outros cursos e o diálogo entre áreas de conhecimentos diversas, possibilitando a fruição de novas ideias. Outras são específicas do Departamento de Artes Corporais e do Instituto de Artes, que trazem o estudo do ensino da arte e mais especificamente o ensino da dança: Fundamentos Filosóficos da Arte, Psicologia e Desenvolvimento aplicado as Artes, Processos Pedagógicos voltados para o Corpo na Arte, Educação através da Arte e TCC em Arte Educação. Apesar de todas as disciplinas do curso terem influência no presente trabalho, neste núcleo estão aquelas que influenciaram-no mais diretamente, por estarem mais dirigidas aos estudos dos fundamentos e práticas do ensino inclusivo da dança.

4 - Práticas de Ensino: as disciplinas que integram esse núcleo promovem a experimentação da ação educativa e a avaliação do fazer docente, por meio de estratégias de leitura, análise, práticas reais ou simulações de práticas pedagógicas. As disciplinas Ateliê de Prática e Ensino da Dança I, II, Dança do Brasil II: Prática e Ensino, Técnica III: Prática, Análise e Ensino da Dança e Ateliê de Criação IV compõe primordialmente esse núcleo. 
Conceição | Conception

Revista do Programa de Pós-Graduação em Artes da

Cena, Universidade Estadual de Campinas

Performing Arts Graduate Program Journal, University of

Campinas

5. Estágio Curricular Supervisionado: O estágio curricular supervisionado acontece nos últimos 4 semestres da formação do licenciado, perfazendo um total de 435 horas. Compreende atividades articuladas e complementares, das quais 195 horas estão sob a coordenação no Departamento de Artes Corporais do IA e as demais 240 horas, sob a coordenação da Faculdade de Educação. São oferecidas 4 disciplinas que se dirigem ao estudo, compartilhamento, orientação, reflexão e avaliação dos exercícios e práticas docentes. É um espaço privilegiado de articulação dos conhecimentos, saberes e competências desenvolvidas nos demais Núcleos de Aprendizagem, mediado por docentes supervisores.

6. Atividades Científico Culturais: este núcleo envolve o aluno em atividades orientadas a debates sobre o papel da dança em seu contexto e para se problematizar o campo de atuação do artista e do professor/licenciado na área. Os alunos podem desenvolver projetos e ações a partir de temáticas atuais - noções de corpo, abordagens contemporâneas da cena, pedagogias da dança -, buscando desenvolver relações com o ensino, a pesquisa e a extensão.

7. Eletivas: existe uma gama de disciplinas oferecidas no próprio Instituto de Artes da Unicamp e em outras Unidades de Ensino que podem ampliar e/ou aprofundar demandas formativas conforme o interesse dos alunos do curso de dança.

A partir dessas colocações, pode-se perceber que as reflexões instigadas pela universidade através das disciplinas do curso, principalmente aquelas voltadas para a licenciatura, têm como sentido preparar um profissional para trabalhar o corpo de quem dança de maneira a permitir a integração do corpo e da mente. No viés educacional, como diz Stuart, um profissional com essa formação possui conhecimentos pedagógicos para atuar no ensino de diferentes grupos sociais e pessoas com diversas necessidades. "Com esta iniciativa, democratizava-se a dança: no limite, qualquer um podia ser bailarino, e a dança deixava de atrelar-se a uma 
Conceição | Conception

Revista do Programa de Pós-Graduação em Artes da

Cena, Universidade Estadual de Campinas

Performing Arts Graduate Program Journal, University of

Campinas

escola para pertencer ao corpo de quem estivesse se movimentando." (STUART,1997, p. 199).

Neste trabalho foi considerada a individualidade de cada corpo, de modo que “a multiplicidade e a diversidade caracterizam esta dança, com corpos híbridos nascidos da contaminação entre fontes culturais, técnicas corporais e gêneros artísticos distintos" (NUNES, 2004/2005, p.46). O ensino inclusivo da dança vem no sentido de utilizar saberes e movimentações próprias dos indivíduos para que, a partir de direcionamentos do professor, percebam que é possível fazer dança e trabalhar para aprimoramento da sua individualidade seja qual for a idade ou havendo ou não uma deficiência.

Seguem algumas reflexões sobre a relação da dança com idosos e com deficientes visuais, com relatos da prática de ensino para esses grupos, nos quais foi utilizada a dança contemporânea como linguagem a ser trabalhada e ensinada, escolhida por ser a referência mais próxima às autoras deste trabalho e por ser um entendimento da dança que tem como preceito a autorreflexão e o autoconhecimento.

\section{Dança para idosos}

Velhice é um destino, e quando ela se apodera da nossa própria vida, deixa-nos estupefatos. "O que se passou, então? A vida, e eu estou velho"(BEAUVOIR, 1970, p. 347).

A dinâmica da população mundial, segundo dados da ONU (Organização das Nações Unidas) referentes a 2011 e de outros órgãos internacionais, mostra que continuamente o contingente de pessoas idosas segue aumentando, trazendo previsões de que, até 2021, a população global de idosos será de 1 bilhão. No Brasil, o estudo disponível e mais recente a respeito da população de idosos no país traz também dados de 2011. Nele é dito que tínhamos até então uma população de idosos 
Conceição | Conception

Revista do Programa de Pós-Graduação em Artes da

Cena, Universidade Estadual de Campinas

Performing Arts Graduate Program Journal, University of

Campinas

de 23,5 milhões, número este que, em comparação ao estudo anterior de 2009, mostra uma taxa de aumento de 7,6\%, o que significa o acréscimo de mais de 1,8 milhão de pessoas na faixa etária a partir de 60 anos - idade que, segundo a Organização Mundial e Saúde (OMS), uma pessoa é classificada como idosa.

Os dados apresentados acima vêm para enfatizar que a população brasileira, assim como a mundial, cada vez mais envelhece e assim cada vez mais precisa de um olhar atencioso e cuidadoso para si, pois "uma das maiores conquistas culturais de um povo em seu processo de humanização é o envelhecimento de sua população, refletindo uma melhoria das condições de vida" (Coordenação Geral dos Direitos do Idoso, 2011). Desse modo, é parte integrante da evolução social e humana de uma sociedade a reflexão e a prática de atividades e políticas públicas voltadas para o idoso.

Neste texto se falará do processo de envelhecimento e será relatada uma experiência docente do ensino de dança para idosos. Trata-se de uma oficina de dança contemporânea realizada dentro do Programa UniversIDADE da Unicamp, que é um programa de extensão voltado tanto para os idosos - pessoas de 60 anos ou mais - como para a meia idade - pessoas a partir de 50 anos -, pois tem como intuito propiciar maior qualidade de vida ao idoso e preparar quem ainda não o é para entrar nessa etapa da vida. O UniversIDADE tem como slogan "um programa para a longevidade", afirmando portanto o interesse do programa em existir de forma contínua e ter importância para aqueles que participam dele. Para este tópico, diferentemente do restante do artigo, se usará a escrita na primeira pessoa, por se tratar do relato pessoal de uma das autoras deste trabalho; ao final também estarão alguns relatos das alunas que participaram das aulas de dança contemporânea dentro do programa.

O processo de envelhecimento é natural no ciclo de nossas vidas e surge quando, por conta do aumento da idade, se fazem necessárias ressignificações diversas, como por exemplo da autoimagem e dos objetivos de vida alcançados ou não. Não há uma idade definida para início desse processo, por se tratar de algo 
Conceição | Conception

Revista do Programa de Pós-Graduação em Artes da

Cena, Universidade Estadual de Campinas

Performing Arts Graduate Program Journal, University of

Campinas

bastante subjetivo e individual, no entanto é quase unânime que esse processo se inicie por volta dos 60 anos. Isso ocorre por conta das primeiras percepções a respeito das mudanças físicas, sociais e comportamentais e chega aos 60 quando somos oficialmente classificados como idosos, independentemente da autopercepção. É necessário entender que esse processo do envelhecer não chega ao fim aos 60 anos, mas sim segue continuamente à medida que a idade aumenta e as mudanças físicas e sociais se tornam mais perceptíveis.

Apesar de haver transformações pessoais e sociais em todas as fases da vida por conta do também natural processo de amadurecimento pessoal e biológico -, no envelhecer elas vêm em maiores proporções, simplesmente pelo fato de a pessoa ser agora considerada velha numa sociedade que preza pelo novo, pela jovialidade, pela aparência e pela rapidez. Esse processo é ainda mais complexo para as mulheres, pois um corpo velho não é visto como belo ou útil da maneira como socialmente e inconscientemente é construído o papel da mulher, apesar da persistência das lutas feministas pela quebra desse paradigma. Como Beauvoir diz:

Nem na literatura, nem na vida, encontrei qualquer mulher que considerasse sua velhice com complacência. Do mesmo modo, nunca se fala em "bela velha"; no máximo se dirá "uma encantadora anciã". Ao passo que admiramos certos "belos velhos"; o macho não é uma presa; não se exige dele nem frescor, nem doçura, nem graça, mas a força e a inteligência do sujeito conquistador; os cabelos brancos e as rugas não contradizem esse ideal viril (BEAUVOIR, 1970, p. 364. Grifo autora).

Segundo a bibliografia especializada em psicologia do envelhecimento e estudos sobre o bem-estar subjetivo em idosos entende-se que "os indivíduos mais velhos tornam-se naturalmente depositários de memórias pessoais e coletivas e, portanto, ricos de um patrimônio que chamaríamos de experiência humana." (VIEIRA, 2009.p.20). Por conta dessa experiência e dos anos de vida é esperado, durante a velhice, que ocorram ressignificações e transformações comportamentais e psicológicas; para isso a pessoa idosa pode buscar atividades que propiciem esse 
Conceição | Conception

Revista do Programa de Pós-Graduação em Artes da

Cena, Universidade Estadual de Campinas

Performing Arts Graduate Program Journal, University of

Campinas

novo olhar sobre a existência (VIEIRA, 2009). Por exemplo, muitos irão buscar melhor qualidade de vida e, no caso do encontro com a dança, aprimorar e desenvolver o contato consigo e com os outros, a propriocepção e a sensibilidade da criatividade.

Estudando, de modo vertical, na universidade os processos de aprender e ensinar danças, aprendi a olhar um corpo que dança ou se movimenta e a identificar suas dificuldades, excelências e principalmente a perceber por onde começar a prestar auxílio para o melhor aproveitamento e desempenho de algum movimento. Atuando na dança também como bailarina vejo que é uma importante linguagem artística como forma de expressão e autoconhecimento, já que estimula a conexão das diferentes dimensões estruturais, sensoriais, cognitivas, emocionais, relacionais entre outras implicadas na experiência do movimento. Assim "movemo-nos em decorrência deste ou daquele desejo, impulsionados por tal ou qual motivação, e a raiz desse fenômeno está em razões primordiais de sobrevivência e na procura de prazer." (BERTAZZO, 2003, p. 3). Desse modo, acredito que a dança deveria estar presente na vida das pessoas em geral, não com o único interesse de se tornar bailarino profissional mas como meio para melhoria da qualidade de vida.

A ideia de oferecer o ensino da dança contemporânea para o indivíduo idoso surgiu, como mencionado na introdução deste tópico, por acreditar que esta tenha a capacidade de propiciar aumento da qualidade de vida. Nas aulas ministradas por mim dentro do programa UniversIDADE, a partir de sequências de movimento, estimulei o desenvolvimento da consciência corporal e o refinamento dos próprios movimentos, a partir do contato de cada aluno consigo - uma autopercepção de suas sensações, sentimentos e vontades - e, incentivando a expressividade do corpo. Trazendo a dança por meio de movimentações simples, de forma que fosse possível para as alunas fazerem uma conexão entre os movimentos cotidianos e os que eram feitos em sala, para que o estudo da dança contemporânea não se tornasse abstrato demais, e sempre lembrando-as de que tais movimentos já faziam parte do repertório de cada uma. 
Conceição | Conception

Revista do Programa de Pós-Graduação em Artes da

Cena, Universidade Estadual de Campinas

Performing Arts Graduate Program Journal, University of

Campinas

É de extrema importância no ensino da dança que o professor conheça seus alunos, seus nomes, suas limitações, para que o ambiente da sala de aula seja mais próximo entre os ambos e com isso a situação de ensino-aprendizagem se torne mais agradável. Sobretudo no ensino de dança às pessoas mais velhas isso se faz necessário; quem deseja trabalhar com esse público precisa ter conhecimento das alterações naturais que ocorrem no corpo ao envelhecer, como por exemplo a diminuição da viscosidade do líquido sinovial nas articulações ou da capacidade de ventilação pulmonar (VITTA, 2000). Além do conhecimento geral do corpo idoso, é preciso saber das dificuldades e saúde dos próprios alunos e com isso preparar conscientemente exercícios que auxiliem na promoção da saúde psicofísica, sem se esquecer de estimular a autonomia, aspecto que não se faz necessário apenas para as práticas corporais, “(...) tanto a saúde física como a funcionalidade exercem forte impacto sobre a qualidade do envelhecimento, mas que não respondem pela complexidade inerente ao envelhecimento bem sucedido." (VIEIRA, 2009, p. 26).

Eram oito alunas que frequentavam a oficina, que aconteceu às sextas-feiras, nas salas do curso de dança da Unicamp, durante todo o segundo semestre de 2016. No início das minhas aulas nos sentamos em roda e fizemos as apresentações, as quais foram muito importantes para eu saber como desenvolver os próximos encontros. Nessa apresentação cada aluno dizia se já tinha feito aula de dança, se já conhecia a dança contemporânea, bem como se possuía restrições ou condições médicas e também contava um pouco de si, do que gosta, se mora sozinho, se tem netos, etc. Algumas alunas faziam, concomitantemente ao período de aulas da minha oficina, aulas de dança de salão, portanto já tinham contato com o corpo e a dança; entretanto essas mesmas e o restante da classe se queixaram bastante de dores que, pela descrição, logo percebi que eram devido à falta de alongamento. Por exemplo, não conseguir ficar descalço por muito tempo por sentir dor "na parte de trás das pernas". Assim passei a usar exercícios de alongamento não apenas como aquecimento, mas como conteúdo de aula, repetindo-os a cada encontro e mostrando que pode-se levar isso para o cotidiano. 
Conceição | Conception

Revista do Programa de Pós-Graduação em Artes da

Cena, Universidade Estadual de Campinas

Performing Arts Graduate Program Journal, University of

Campinas

Após o alongamento, seguindo com a prática de dança, vinham os exercícios com intuito de correção postural e técnica de dança; depois algumas sequências mais longas e de movimentos mais interligados para trabalhar a memória, a coletividade, a coordenação motora e o senso espacial; por fim a última parte da aula era construída para dar vasão a criatividade das alunas, por meio da criação de movimentos ou pela apropriação de uma sequência feita por mim, afim de trazer a autonomia e identidade de cada aluna para uma dança rica de significados individuais. Durante cada aula, em diferentes períodos, eu pedia para as alunas fecharem os olhos e se concentrarem em suas respirações e na percepção do corpo naquele momento; fazíamos isso no início ou ao longo da aula, percebendo as mudanças no estado corporal após algum exercício. A expressividade individual surgia a partir das repetições e apropriação dos movimentos, processo alimentado pelos direcionamentos que eu dava para que elas se deixassem levar pela naturalidade da própria movimentação.

Minha oficina recebeu o nome de "Vivência em Dança Contemporânea". Nela, aprendi muito, principalmente sobre a atitude em sala de aula como professora e a espera pelo tempo do aluno em assimilar os conteúdos. A cada novo exercício conversava com a turma para saber como havia sido para elas realizarem a proposta e como haviam se sentido após experienciar a fruição do fluxo de movimento. Com esse incentivo que eu dava para elas se colocarem e compartilharem suas percepções, percebi que todas se animavam muito em relatar suas sensações; portanto coloco aqui alguns relatos escritos por elas como forma de mostrar o ponto de vista do idoso que pratica a dança contemporânea.

\section{Depoimentos}

Nome: E.M.C. - Idade: 61 anos - Sexo: F 
Conceição | Conception

Revista do Programa de Pós-Graduação em Artes da

Cena, Universidade Estadual de Campinas

Performing Arts Graduate Program Journal, University of

Campinas

“O primeiro contato com a Dança Contemporânea foi dentro do Programa UniversIdade nesse segundo semestre/2016. Gosto de fazer atividades físicas e tive interesse de participar das aulas para conhecer. As aulas começam com uma série de exercícios de alongamento. Como já fiz várias atividades como: Yoga, Tai Chi, Dança Indiana, tenho facilidade em fazer os exercícios físicos e os movimentos através da dança.

Percebo que a cada aula tenho mais percepção do meu corpo e, também, dos meus limites, não me excedendo nos exercícios. Os movimentos de dança exigem uma atenção com todo corpo e o que podemos fazer para manter uma relação mais agradável consigo mesmo. A mudança corporal que tenho percebido é a agilidade para fazer os exercícios e a possibilidade de poder dançar com criatividade. O meu sentimento durante o tempo que estou dançando é de poder acreditar que sou capaz de me expressar com o corpo através dos movimentos, sem colocar limites.

Neste grupo, também, tenho percebido como podemos nos relacionar e observar o outro em seus movimentos. Minha autopercepção da aula é que precisamos conhecer mais nosso corpo, como tensões em alguma parte do corpo, prestar atenção no caminhar, na respiração e coordenação dos movimentos. Percebo que durante a aula que a sequência dos exercícios proporciona soltar o corpo para melhor realizar os movimentos da dança; consigo relaxar as tensões e no final sinto que o corpo está mais leve e com uma expressão diferente de quando comecei as atividades."

Nome: S.A.L - Idade: 62 anos. - Sexo: F

"Eu não tive oportunidade de fazer ballet ou outro tipo de dança em minha infância/adolescência, mas a dança sempre me encantou. Às vezes pensava que o ballet me traria ritmo, leveza e elegância, mas sentia um imenso acanhamento em buscá-lo a esta altura de minha vida. O Programa Universidade nos apresentou algumas alternativas de danças e eu me encantei com tais possibilidades. As aulas de dança contemporânea me trazem alegria, leveza e serenidade. Sou muito 
Conceição | Conception

Revista do Programa de Pós-Graduação em Artes da

Cena, Universidade Estadual de Campinas

Performing Arts Graduate Program Journal, University of

Campinas

inquieta, mas ao término das aulas estou sempre muito tranquila, relaxada. Sinto um prazer muito grande quando chega a sexta-feira, nosso dia de aula [...]. Sinto confiança, acolhimento e nestas horas não temos idade, apenas desejo e prazer em explorar os movimentos e sentir o próprio corpo.

Penso que a nossa soltura e entrega aos movimentos dependem ou são mais facilitados quando se estabelece um vínculo com o professor.!"

Nome: R.C.M.G - Idade: 60 anos. - Sexo: F

“O processo do envelhecimento é profundamente marcado pelas mudanças que se dão em nosso corpo. A dificuldade de aceitação deste corpo envelhecido, com as limitações decorrentes deste processo, é sempre motivo de grande insegurança e sofrimento. Por isso, descobrir a capacidade de executar movimentos novos, que nunca sequer tinha tentado, por um corpo já marcado pelo tempo foi fantástico! Coordenar movimentos, repetir sequências, imprimir graça e leveza, criar e tantas outras experiências inusitadas tornaram a experiência prazerosa e inesquecível!"

Nome: C.R.B. - Idade: 65 anos. - Sexo: F

“Gostei muito da oficina, senti que os exercícios são eficientes e os movimentos rítmicos me causam bastante prazer, sinto que fortalecem e tem agregado bastante mobilidade. Consigo perceber uma boa melhora nos meus movimentos cotidianos. Quero destacar também que os movimentos localizados, tais como o pescoço, as mãos, pés e dedos tem me levado a uma boa destreza física. Um ponto que observo como bastante eficiente é que o movimento corporal repercute bem na minha atividade mental, percebo que os movimentos além do físico ajudam também no desenvolvimento mental. Claro que alguns movimentos apresentaram alguma dificuldade, mas a paciência, atenção e dedicação da instrutora foram fundamentais para que eu conseguisse acompanhar a atividade." 
Conceição | Conception

Revista do Programa de Pós-Graduação em Artes da

Cena, Universidade Estadual de Campinas

Performing Arts Graduate Program Journal, University of

Campinas

\section{Dança para deficientes visuais}

As reflexões que se seguem tiveram como antecedente um trabalho de iniciação científica, realizado pela pesquisadora em questão e orientado pela Prof. ${ }^{a}$ Dra. Mariana B. M. Andraus. Sendo financiado pela Fapesp e realizado na Unicamp, o trabalho foi intitulado "Propriocepção e consciência corporal para pessoas com deficiência visual" e constituiu-se de uma pesquisa teórica sobre os temas relacionados, acompanhado de um trabalho prático, de forma que a pesquisadora trabalhou a dança com deficientes visuais de dois lugares que forneceram espaço: o Laboratório de Acessibilidade da Unicamp (LAB), em Campinas/SP e o Instituto Riopretense dos Cegos Trabalhadores, em São José do Rio Preto/SP. A iniciação científica teve duração de um ano, sendo seu início em março de 2015 e o término no mesmo mês do ano seguinte. Após esse um ano de trabalho, seguiu-se um ano de voluntariado dentro do Instituto. As aulas aconteciam uma vez por semana em cada local, tendo duração de uma hora semanal. Ao todo, houve cinco participantes, entre a faixa etária de 25 e 60 anos, sendo um participante cego no LAB e quatro no Instituto: um com baixa visão, dois cegos com a percepção de vultos e um com cegueira total, mas todos com a deficiência adquirida. De modo geral, as aulas eram divididas em alongamento, relaxamento e percepção corporal, exercícios criativos e finalizavam com uma roda de conversa, em que eles podiam compartilhar as experiências apreendidas dentro e fora das aulas. A pesquisa também resultou em apresentações nos congressos PIBIC - UNICAMP/2015 e SBPC (Sociedade Brasileira para o Progresso da Ciência) /2016; e no aprendizado para a pesquisadora sobre quem é esse público tão imenso e especial.

A deficiência visual não é igual em todos os indivíduos, ela pode acontecer, influenciar e interferir na vida de uma pessoa de diversas maneiras. Quando a pessoa nasce cega, a deficiência é denominada congênita e quando ocorre após o nascimento, é denominada adquirida. Isso pode acontecer com qualquer pessoa e em 
Conceição | Conception

Revista do Programa de Pós-Graduação em Artes da

Cena, Universidade Estadual de Campinas

Performing Arts Graduate Program Journal, University of

Campinas

qualquer idade, devido a acidentes, doenças, como diabetes, dentre outras causas. Além disso, há diversos graus da deficiência, entre o vidente e o cego e o que define isso chama-se acuidade visual, que pode ser definido por médicos, através de exames. Apesar desses termos classificarem as deficiências em poucas categorias, as possibilidades são muito mais complexas, já que um cego é diferente do outro, dependendo de como ocorreu a perda, com que idade, como a família auxiliou e se a pessoa consegue perceber luminosidade e vultos. Assim, como cada vidente enxerga o mundo à sua maneira, a partir de suas percepções, os cegos também possuem as suas peculiaridades, sua individualidade. Dessa forma, ao trabalhar com deficientes visuais, deve-se saber qual a história individual de cada um e como ocorreu a perda da visão, pois esses conhecimentos sobre os alunos ali presentes interferem no modo de ensiná-los.

Essa individualidade deve ser considerada ao preparar as aulas, pois, em alguns casos, a deficiência visual é acompanhada de outras dificuldades corporais. Além disso, há o cuidado em não colocar todos os deficientes visuais em uma redoma, considerando-os com o mesmo nível de conhecimento, de dificuldades ou de dedicação. Cada um deles possui seus interesses próprios, vontades, competências e habilidades desenvolvidas e a desenvolver. Dessa maneira, a história de cada um, inclusive as histórias corporais, interfere no momento de elaborar as aulas, já que em uma sala de aula há sempre os alunos com mais ou menos facilidade em determinados assuntos. É importante ressaltar também que antes da deficiência, existe o ser humano, que muitas vezes é apagado pela visão geral que a população possui, e que, por sua vez, predetermina suas necessidades, vontades e limites, decidindo pelo indivíduo que ali existe, como se este não conseguisse tomar decisões, possuir desejos e vontades, ou até, ter uma vida comum.

A dança na vida de um deficiente pode ser vista de diversas formas: atividade corporal, como forma de exercitar o corpo; atividade criativa/artística, com o intuito de criar e experienciar a dança e como atividade social, em que os alunos podem realizar uma atividade em grupo, podendo interagir 
Conceição | Conception

Revista do Programa de Pós-Graduação em Artes da

Cena, Universidade Estadual de Campinas

Performing Arts Graduate Program Journal, University of

Campinas

com outros deficientes ou com pessoas sem deficiências; e essas três formas não precisam ser trabalhadas separadamente, de maneira que uma professora de dança pode conciliá-las numa aula, já que todas são de grande importância e desenvolvem diversas habilidades que permitem melhorias na vida de um ser humano, com ou sem deficiência.

Ao perder a visão, muitas pessoas perdem a referência de seu corpo no espaço, como está disposto e o seu deslocamento, pois existe uma predominância sensorial no olhar (FIGUEIREDO, 1999). Dessa forma, as atividades corporais podem ampliar essa noção, além de auxiliar no desenvolvimento do equilíbrio, que possui grande dependência da visão. A dança, em específico, possui métodos e técnicas que focam na propriocepção, consciência e expressão corporal. Ademais, há diversos trabalhos de criação e explorações corporais que auxiliam na soltura do corpo, evitando a dependência do olhar externo e da imitação, permitindo que um deficiente visual entregue seu corpo a dança sem tantos medos. "As atividades de dança para os deficientes visuais devem ser criativas, lúdicas, com movimentos que promovam a autonomia deste corpo." (CAZÉ, OLIVEIRA, 2008, p.299).

Ao trabalhar dança com deficientes visuais é possível perceber, após alguns meses de trabalho, algumas mudanças em seus corpos, tanto em aula, quanto no cotidiano. Muitas vezes o deficiente visual tende a enrijecer o corpo, por não saber o que pode lhe acontecer em seu trajeto, sendo também comum que leve a cabeça e os ombros para frente. Essa postura e esse enrijecimento dos músculos podem causar dores e tensões musculares desnecessárias, que podem ser diminuídas com trabalhos corporais. Outro ponto é a dificuldade de formar sua consciência corporal, já que muitas coisas que sabemos sobre nosso corpo são vistas no espelho ou tendo como referência a visão de um corpo alheio ao nosso. A dança, principalmente em técnicas somáticas, trabalha essa consciência corporal através de percepções internas e o toque em si mesmo ou no corpo do outro, o que pode ser de grande valia para o deficiente visual. 
Conceição | Conception

Revista do Programa de Pós-Graduação em Artes da

Cena, Universidade Estadual de Campinas

Performing Arts Graduate Program Journal, University of

Campinas

Um aspecto de grande importância ao se trabalhar dança com deficientes visuais é o modo como fazê-lo. A pedagogia tradicional predominou na história da dança, mediando os processos de aprendizado com o uso de espelhos e tendo o corpo do professor como referência, fazendo com que os domínios de uma técnica fossem dependentes da visão. Porém, hoje existem muitas outras abordagens didático-metodológicas que não possuem essa total dependência da visão, inclusive no ensino do balé clássico, permitindo que o deficiente visual tenha acesso a diferentes técnicas e estilos de dança. Portanto, o professor que deseja trabalhar com esse público deve pensar em seu vocabulário com os alunos e nos exemplos e imagens que traz como referência, pois, muitas das imagens corporais que são utilizadas, também baseiam-se na visão. $O$ toque e a audição são as maiores referências para o aluno cego.

Outra reflexão importante trazida no livro de Maria Lúcia Amiralian está no olhar que quer estudar e compreender o mundo de um cego, porque este tende a usar o seu mundo de vidente como referência para observar o outro. Querer ajudar o cego tornando-o semelhante a um vidente não tem se mostrado o melhor caminho. Essas observações feitas pela autora do livro servem para ajudar um professor ou qualquer outra pessoa que esteja trabalhando com um cego ou com pessoas que possuem outras deficiências a repensarem seus atos, pensando na melhor maneira de tornar a vida daquela pessoa melhor, sem tentar fazê-la viver segundo a sua própria vida e os seus modos. (ANDRAUS, FONSECA, 2016, p. 7)

É possível afirmar que a dança proporciona grandes resultados. Entretanto, estes dependerão de paciência de ambas as partes, pois as mudanças acontecem ao longo do tempo, da dedicação, da persistência, do contato direto entre professor e aluno e entre eles mesmos (alunos). Caso contrário, o trabalho com a dança transforma-se em uma prática meramente mecânica. 
Conceição | Conception

Revista do Programa de Pós-Graduação em Artes da

Cena, Universidade Estadual de Campinas

Performing Arts Graduate Program Journal, University of

Campinas

\section{Considerações Finais}

“A arte reinventa o corpo constantemente [...] arte nos devolve, de certa forma, a nossa humanidade. Porque a dança permite a visibilidade extrema ao corpo em seus modos de representação" (NUNES, 2004/2005. p. 46). Partindo desse pensamento de Sandra Nunes e sua bela escolha de palavras, é possível notar a grande influência que a dança pode exercer na vida de um ser humano, principalmente na vida daqueles que possuem alguma dificuldade, especialmente física e que, muitas vezes, creem estar impossibilitados de fazê-la.

As duas pesquisadoras em questão realizaram atividades com os públicos indicados, de maneira que puderam observar grandes avanços nessas pessoas, tanto físicos quanto criativos e comportamentais. Além disso, os alunos valorizaram o trabalho coletivo, que permitiu que estivessem em contato com outras pessoas. Do qual puderam observar que

O desenvolvimento da competência sensório-motora ocorre ao longo da vida, não se restringe apenas ao período da infância (LAKOFF; JOHNSON, 1999; LLINÁS, 2002). Este fato reforça a importância da prática da dança mesmo na vida adulta. Para os indivíduos cegos, esta prática torna-se ainda mais relevante pelas interações espaço/temporais e corporais com os processos mentais (CAZÉ e OLIVEIRA, 2008, p. 294).

Além disso, notaram a individualidade de cada aluno, conforme mencionado no texto, de modo que num mesmo espaço, pessoas com características semelhantes, demonstraram diferentes interesses e aproveitamentos do conteúdo trabalhado em sala de aula, referendando o que diz Ivaldo: “A arte transforma indiscutivelmente o indivíduo. Ela informa, ela nos diferencia uns dos outros, ela modifica nossos desejos" (BERTAZZO, 2003, p.11). Ficou claro que havia diferenças na história de vida de cada um e no contato prévio com a dança, uma das expressões da arte; já que no mesmo grupo de alunos alguns já haviam feito aulas de dança em outros 
Conceição | Conception

Revista do Programa de Pós-Graduação em Artes da

Cena, Universidade Estadual de Campinas

Performing Arts Graduate Program Journal, University of

Campinas

momentos de suas vidas ou até concomitantemente às aulas mencionadas neste trabalho, e outros que ainda não haviam possuído esse contato.

Para as pesquisadoras, estar com os grupos nos quais as pesquisas foram realizadas, ensinando dança, foi uma experiência realmente gratificante, pois podese ver efetivamente o impacto da dança na vida de quem possui algum tipo de limitação física - aqui em específico a dança para idosos e para deficientes visuais. Assim muito do que foi colocado nas aulas vai de encontro com o entrar em contato consigo mesmo, percebendo seu corpo, seus estados emocionais e despertando-se para a expressão através do movimento. O treinamento físico, de acordo com as possibilidades de cada um é indicado para se conseguir um tônus corporal, um estado de prontidão para o movimento, por fim, o estar em grupo, aumentando ainda mais o sentido de pertencimento. A prática docente traz muitos aprendizados sobre como se fazer entender pelos alunos, conseguir a rapidez de improvisar algum exercício que se percebe como necessário ali, naquele momento, e a organização e gradação das atividades. Nesta pesquisa, além desses aprendizados inerentes ao trabalho de professoras, foi possível também aprender a ressignificar as dificuldades e a maneira como lidar com os alunos e a perceber que a dança, obviamente, não traz respostas ou benefícios para tudo o que precisamos, mas torna o caminho das descobertas e assimilações muito mais agradável.

\section{REFERÊNCIAS}

ANDRAUS, M. B. M., FONSECA T. C. Propriocepção e consciência corporal para pessoas com deficiência visual. FAPESP Proc.2014/21807-2. Campinas, 2016.

BEAUVOIR, S. (1970). A Velhice. Trad. Maria Helena de Franco Martins. Editora Nova Fronteira (Rio de Janeiro). 1990.

BERTAZZO, I. A importância da dança na formação do cidadão (2003). Disponível em:

https://culturaecurriculo.fde.sp.gov.br/Administracao/Anexos/Documentos/4201 
Conceição | Conception

Revista do Programa de Pós-Graduação em Artes da

Cena, Universidade Estadual de Campinas

Performing Arts Graduate Program Journal, University of

Campinas

00823115851A\%20import\%C3\%A2ncia\%20da \%20dan\%C3\%A7a\%20na \%20forma \%C 3\%A7\%C3\%A3o\%20do\%20cidad\%C3\%A3o.pdf Acesso em: 25/10/2018.

BRASIL. Dados sobre o envelhecimento no Brasil. Coordenação Geral dos Direitos do Idoso (Secretaria de Direitos Humanos). 2011. Disponível em http://www.sdh.gov.br/assuntos/pessoa-idosa/dados-estatisticos. Acesso em 03/11/2016.

CAZÉ, C. M. de J. O., OLIVEIRA, A. da S. Dança além da visão: possibilidades do corpo cego. Pensar a prática (Goiânia), v. 11, n. 3, 2008. Disponível em: http://www.revistas.ufg.br/index.php/fef/article/viewArticle/3592 Acesso em $10 / 9 / 2014$.

FIGUEIREDO, V. M. C., TAVARES, M. da C. G. C. F., VENÂNCIO, S. Olhar para o corpo que dança: um sentido para a pessoa portadora de deficiência visual. Movimento (Porto Alegre), ano V, n. 11, 1999.

LIMA, M. D., JAEGER, A. A. Dançando a corporeidade da criança com Síndrome de Down. Santa Maria: Revista Kinesis. p.96-186. Nov. 2002.

NUNES, S. M. Fazer dança e fazer com dança: perspectivas estéticas para os corpos especiais que dançam. PONTO DE VISTA, Florianópolis, n. 6/7, p. 43-56, 2004/2005.

STUART, I. A Experiência do Judson Dance Theater. In: PEREIRA, R.; SOTER, S. (Org.). Lições de Dança 1. Rio de Janeiro: UniverCidade. 1997. pp. 191-203.

Trinity Laban Conservatoire of Music and Dance. Dance towards well-being in the Third Age. Commisioned by the London Thames Gateway Dance Partnership. Inglaterra: $\quad$ Londres. $2010 . \quad$ Disponível em: http:/ / www.trinitylaban.ac.uk/ news/latest-news/dancing-towards-wellbeingthird-age. Acesso em 17/11/2016.

VIEIRA, S. P. O Bem Estar Subjetivo em Nonagenários: um estudo qualitativo. Campinas. Dissertação de mestrado, Programa de Pós-Graduação em Gerontologia da Faculdade de Ciências Médicas/FCM-Unicamp, 2009.

VITTA, A. Atividade Física e Bem-Estar na Velhice. In: NERI, A. L.; Freire, S. A. (Org.). E por falar em boa velhice. Campinas - SP. Papirus. 2000. pp. 81-89. 